\title{
Perfil de estudantes encaminhados para apoio pedagógico
}

\author{
Andreia Osti' \\ Universidade Estadual Paulista, SP, Brasil \\ Selma de Cássia Martinelli² \\ Universidade Estadual de Campinas, SP, Brasil
}

\begin{abstract}
Resumo: $O$ presente artigo analisou um grupo de $37 \mid$ estudantes, que cursava do $I^{\circ}$ ao $5^{\circ}$ ano escolar do ensino fundamental, de escolas públicas de uma cidade do interior de São Paulo, que frequentavam atendimento pedagógico por apresentarem baixo desempenho escolar. Objetivou-se avaliar nesses alunos a característica do grupo em relação à idade, série, gênero e as dificuldades escolares específicas apresentadas. Os resultados indicam que a maior parte dos estudantes encaminhados são meninos, o que configura prevalência quanto ao gênero. Em relação ao ano escolar, 59,7\% estão matriculados entre $\circ 1^{\circ}$ e $3^{\circ}$ ano e $40,3 \%$ entre $\circ 4^{\circ}$ e $5^{\circ}$ ano do fundamental. Dos alunos que apresentam defasagem entre idade e série, $70,2 \%$ destes foram identificados com problemas na escrita, $83,9 \%$ em matemática, e $44 \%$ em leitura.
\end{abstract}

Palavras-chave: educação; desempenho; reforço escolar; ensino, intervenção.

\section{PROFILES OF STUDENTS WHO ARE FORWARDED TO PEDAGOGICAL SUPPORT}

\begin{abstract}
The following article analyzed a group of 37 I students, who attend from Ist to 5 th grade of elementary school, from public schools in a city in located in the interior of São Paulo's state, who were part of pedagogical care by virtue of their poor academic performance. The aim of this study was to evaluate these groups of students according to their characteristics such as age, grade, gender and the specific learning difficulties presented. The results indicate that most of the referred students are boys, which sets prevalence according to gender. In relation to the school year, $59.7 \%$ are enrolled between the Ist and 3rd year and $40.3 \%$ between the 4 th and 5 th grade of elementary school. Amongst the students who have presented a lag between age and grade, $70.2 \%$ of these were identified with problems in writing, $83.9 \%$ in mathematics and $44 \%$ in reading.
\end{abstract}

Keywords: education; performance; tutoring; teaching; intervention.

\section{ESTUDIANTES ENCAMINADOS PARA APOYO PEDAGÓGICO}

Resumen: El presente artículo analizó un grupo de $37 \mathrm{I}$ estudiantes, que cursaba del $\mathrm{I}^{\circ}$ al $5^{\circ}$ año escolar de la enseñanza fundamental, de escuelas públicas de una ciudad del interior de São Paulo, que frecuentaban el atendimiento pedagógico por presentar bajo aprovechamiento escolar. Se tuvo como objetivo evaluar en esos alumnos la característica del grupo en relación a la edad, serie, género y las dificultades escolares específicas presentadas. Los resultados indican que la mayoría de los estudiantes encaminados son

'Endereço para correspondência: Andreia Osti, Universidade Estadual Paulista, Departamento de Educação, Avenida 24A, 1515, Bela Vista, Rio Claro, SP. CEP: 13506-900. E-mail: aosti@rc.unesp.br. 
niños, lo que configura prevalencia en cuanto al género. En relación al año escolar, $59,7 \%$ están matriculados entre el $1^{\circ}$ y el $3^{\circ}$ año y $40,3 \%$ entre el $4^{\circ}$ y el $5^{\circ}$ año del fundamental. De los alumnos que presentan desfase entre edad y serie, $70,2 \%$ de ellos fueron identificados con problemas en la escritura, $83,9 \%$ en matemáticas y $44 \%$ en lectura.

Palabras clave: educación; desempeño; refuerzo escolar; enseñanza; intervención.

\section{Introdução}

Nas últimas décadas o Brasil conseguiu praticamente inserir todas as suas crianças na escola fundamental. No entanto, mesmo com a ampliação do número de vagas no sistema educacional, não houve modificações significativas para tornar o ensino eficiente, uma vez que já naquele momento se apontava para altos índices de repetência e evasão, assim como para a distorção idade/série (Gouvea, 2000). Passado mais de uma década e, de acordo com a Organization for Economic Cooperation and Development - OECD (2012), o Brasil, apesar de ter evidenciado estatisticamente um aumento progressivo no número de estudantes matriculados na educação básica, ainda não consegue atingir resultados satisfatórios em relação ao desempenho escolar desses estudantes.

A qualidade da educação ainda é muito baixa em nosso país, tanto no nível de aprendizado escolar adequado a cada série (Veloso, 2009), como em relação ao domínio das habilidades essenciais para o uso em contexto social mais amplo. É uma realidade, no Brasil, o fato de alunos frequentarem a educação básica e serem incapazes de, ao final do $9^{\circ}$ ano escolar, ler e entender um texto simples ou realizar operações matemáticas rudimentares (Oliveira, 2011). Segundo Felicio (2009), o resultado das avaliações governamentais, realizadas em larga escala, também revelam que o nível de desempenho escolar dos estudantes brasileiros está muito abaixo do esperado.

Essa mesma constatação também foi feita pelo Programa Internacional de Avaliação de Alunos - Programme for International Student Assessment - Pisa (Organization for Economic Cooperation and Development, 2012), ao revelar que o desempenho dos estudantes brasileiros, em leitura, havia piorado se comparado ao ano de 2009. O país somou em 2012, 410 pontos em leitura, dois pontos a menos do que a pontuação obtida na avaliação de 2009, sendo que a média da OECD é de 496 . Isso significa que $49,2 \%$ dos estudantes avaliados não foram capazes de deduzir informações de um texto e não conseguiram compreender nuances da linguagem. Em matemática, apesar de apresentar um pequeno avanço, de 386 para 391 pontos, verificou-se que os estudantes não conseguiam interpretar situações que exigiam apenas deduções diretas da informação dada e não foram capazes de entender percentuais, frações ou gráficos. 0 avanço alcançado pelo Brasil no ano de 2012, em matemática, não foi suficiente para que avançasse no ranking internacional, uma vez que a média da OECD, em 2012, foi de 494 pontos, fazendo com que o Brasil caísse para a $58^{\mathrm{a}}$ posição em matemática.

Dados divulgados pelo Instituto Nacional de Estudos e Pesquisas Educacionais Anísio Teixeira - Inep (2015) sobre as taxas de rendimento na educação básica referentes 
ao ano de 2010, na região Sudeste, apontam que os índices gerais de aprovação no ensino fundamental, do $1^{\circ}$ ao $5^{\circ}$ ano, foram de $93,9 \%$ de aprovação e $5,5 \%$ de reprovação, do $6^{\circ}$ ao $9^{\circ}$ ano de $87 \%$ e $10,5 \%$ respectivamente. Temos um total geral no ensino fundamental, do $1^{\circ}$ ao $9^{\circ}$ ano, de $90,6 \%$ de aprovações e $7,9 \%$ de reprovações. Especificamente em relação às escolas municipais do Brasil temos, do $1^{\circ}$ ao $9^{\circ}$ ano do fundamental, $94,9 \%$ de aprovações e $4,8 \%$ de reprovações e do $6^{\circ}$ ao $9^{\circ}$ ano de $91,3 \%$ de aprovação e 7,4\% de reprovações.

Ao analisar os indicadores de desempenho escolar da Secretaria de Educação do Estado de São Paulo - Seesp (2014), observa-se também mudança nos índices em relação a rede municipal, entre 2010 e 2013, havendo aumento progressivo nas percentagens de aprovação e regressivo nas de reprovação. Em 2010, tínhamos $94 \%$ de alunos aprovados e $5 \%$ de reprovados, em $2011,94,3 \%$ aprovados e $5,1 \%$ de reprovados, em 2012 , $94,9 \%$ aprovados e $4,5 \%$ reprovados e, em $2013,95,3 \%$ aprovados e $4,1 \%$ reprovados.

Apesar dos dados mostrarem aumento no número de aprovações no ensino fundamental, embora não apresentem dados que demonstrem o avanço dos estudantes quanto ao domínio dos conteúdos exigidos pela escola, chama a atenção o fato de ainda existir elevado número de alunos em defasagem de idade/ano escolar e que são encaminhados para reforço escolar. De acordo com o Instituto Nacional de Estudos e Pesquisas Educacionais Anísio Teixeira (2015), em 2009, a defasagem idade/ ano escolar atingiu $46,7 \%$ dos alunos do ensino fundamental e, em 2010 , foi de $53,8 \%$. Em 2012, dos alunos que cursavam o $6^{\circ}$ ano (antiga $5^{a}$ série), 54,3\% apresentaram defasagem entre a idade e o ano escolar cursado e sete milhões de jovens entre sete e 17 anos estavam fora da idade regular para o ano/série que frequentam no ensino básico.

Para Mandelli (2011) , os dados da Avaliação Brasileira do Final do Ciclo de Alfabetização (Prova $A B C$ ) e a Prova Brasil revelam que a porcentagem de alunos com defasagem idade/ano escolar, que apresentam desempenho adequado, é sempre inferior a de alunos com desempenho adequado, mas na idade correta. Especificamente, na Prova $A B C$ de 2011 , enquanto $57,9 \%$ das crianças na idade correta atingiram o desempenho esperado para escrita, $61,8 \%$ em leitura e $47,1 \%$ em matemática, apenas $35,2 \%$ dos defasados aprenderam o conteúdo esperado em escrita, 34,3\% em leitura e $25,7 \%$ em matemática.

Soma-se aos dados apresentados o fato de que diversas pesquisas apontam a diferença no desempenho de meninas e meninos, incluindo estudantes com defasagem escolar (Gregoriadis, \& Tsigilis, 2008; Henriques, 2002). Liederman, Kantrowitz, \& Flannery (2005) ao investigarem as dificuldades de leitura, revelaram haver um predomínio de meninos em relação às meninas com dificuldades. De acordo com a Foundation for People with Learning Disabilities - FPLD (2014), estima-se que existam 286 mil crianças, sendo 180 mil meninos e 106 mil meninas de até 17 anos de idade, no Reino Unido, que apresentam dificuldades de alguma natureza, sobretudo nos conteúdos de leitura, escrita ou cálculo. 
Heitin (2013) identificou nos Estados Unidos diferenças entre os escores obtidos por meninos e meninas na avaliação do Programa Internacional de Avaliação de Alunos (Pisa). $O$ dado apontou que há três anos os meninos superam as meninas em matemática para melhor. Stoet \& Geary (2013), ao analisarem uma década de dados coletados pelo Pisa e cerca de 1,5 milhões de jovens de 15 anos em 75 países, observaram que os meninos tiveram maior pontuação do que as meninas em matemática, mas menor do que elas em leitura. A diferença entre os sexos na leitura foi três vezes maior do que em matemática. Meninos obtiveram as menores pontuações na leitura em todos os países pesquisados e em todas as quatro avaliações do Pisa, nos anos 2000, 2003, 2006 e 2009. Os dados revelam ainda que em alguns países investigados (Austrália, Canadá, Finlândia, Japão, China, Singapura e Taiwan) não houve diferenças entre os sexos com relação ao desempenho em matemática e, em outros (Islândia, Jordânia, Malásia, Qatar e Tailândia), as meninas superaram os meninos no desempenho em matemática. Outro dado interessante apontado por este levantamento foi que, entre os países em que se evidenciou menor diferença entre os sexos com relação ao desempenho em matemática, houve maiores diferenças em relação à leitura e vice-versa.

Outros estudos (Wai, Cacchio, Putallaz, \& Makel, 2010, Halpern, 2012) encontraram melhores resultados dos meninos em matemática, enquanto as meninas obtiveram melhores médias em leitura. Testes de desempenho padronizados também evidenciam que as mulheres obtêm melhores resultados em ortografia e têm melhor desempenho em testes de alfabetização, escrita e conhecimentos gerais (National Center For Education Statistics, 2013).

No Brasil, uma revisão de estudos sobre gênero e desempenho escolar, realizada por Carvalho (2012), afirma que as mulheres obtêm maiores índices de sucesso e que o fracasso escolar é maior entre meninos no ensino fundamental. Outros estudos (Souza, 2007; Dal'Igna, 2007) também indicam que os meninos apresentam maior número de reprovações e mais altos índices de defasagem que as meninas (Palomino, 2004) e são mais frequentemente apontados pelas professoras como alunos com problemas escolares. De forma geral, podemos inferir que os meninos brasileiros, quando comparados às meninas, têm maior número de reprovações e encontram-se em situação de maior defasagem escolar (Pinto, 2012 ), e que frequentemente há maior presença dos meninos nas atividades de reforço escolar e atendimento especial do que meninas (Pinto, 2012; Henriques, 2002).

No Brasil, a taxa de distorção idade/ano escolar no ensino fundamental, de acordo com Instituto Nacional de Estudos e Pesquisas Educacionais Anísio Teixeira (2015), foi de $18,4 \%$ do $1^{\circ}$ ao $5^{\circ}$ ano e de $35 \%$ do $6^{\circ}$ ao $9^{\circ}$ ano. Isso reforça a observação de que, apesar dos dados oficiais indicarem uma crescente aprovação na educação básica, ainda é significativo o número de alunos que fracassam em sua escolarização. As séries que mais apresentam defasagem concentram-se entre o $3^{\circ}(21,6 \%), 4^{\circ}(24,4 \%), 5^{\circ}$ $(25,2)$ e $6^{\circ}$ ano $(38,6)$. O fato de o $6^{\circ}$ ano concentrar o maior índice de defasagem indica, a priori, que a primeira fase do ensino fundamental não está garantindo a apren- 
dizagem dos conteúdos escolares de maneira eficaz, uma vez que ao ingressar no $2^{\circ}$ ciclo ( $6^{\circ}$ ano) há um aumento significativo na distorção de idade e série.

Estudos recentes permitem afirmar que há um crescente número de alunos encaminhados pelas escolas para avaliação especializada por não estarem acompanhando o conteúdo escolar (Osti \& Martinelli, 2014, Pinto, 2012). Como os dados dessa clientela ainda encontram-se muito dispersos, e são bastante incipientes na realidade brasileira, este estudo propôs-se a investigar um grupo de estudantes que foi encaminhado e que frequentava atendimento pedagógico por apresentar baixo desempenho escolar. Optou-se por caracterizar esse grupo em relação à idade, à série, ao gênero e às dificuldades específicas apresentadas.

\section{Método}

\section{Participantes}

Participaram deste estudo 371 estudantes de escolas públicas do ensino fundamental de uma cidade no interior de São Paulo, com idades entre 6 e 15 anos ( $M=9,8$, DP $=1,39$ ) de ambos os sexos, sendo a maioria do sexo masculino $(69,5 \%)$. Os estudantes cursavam do $1^{\circ}$ ao $5^{\circ}$ ano do ensino fundamental e frequentavam um serviço de apoio pedagógico por apresentarem baixo desempenho escolar. Utilizou-se como critério para a análise dos dados a separação da amostra em dois grupos distintos. Um grupo que não apresentava defasagem idade/ano escolar, no momento em que iniciaram seu atendimento no serviço de apoio, e outro que apresentava essa defasagem. Foi considerado defasado aquele estudante que tinha idade de um ano ou mais acima do esperado para o ano escolar cursado.

\section{Instrumento}

A partir da queixa apresentada pela escola, os profissionais do setor de apoio pedagógico, mantido pelo município, realizavam uma avaliação relativa à escrita, leitura e operações aritméticas. Como parte desta avaliação as crianças executavam atividades como: ditado de palavras, escrita de frases e de um texto; produção de escrita espontânea; leitura e interpretação de um texto; resolução de problemas envolvendo as quatro operações e exercícios de lógica. Estas atividades eram propostas de acordo com os conteúdos exigidos para a série cursada pelo estudante. Após as análises, os estudantes eram (ou não) encaminhados para dar prosseguimento ao atendimento no setor de apoio pedagógico.

\section{Procedimento de coleta e análise de dados}

A coleta ocorreu no centro de apoio pedagógico para aqueles estudantes que permaneceram em atendimento após o período de avaliação. Para fins desta análise foram consideradas as avaliações realizadas pelos especialistas do setor de apoio pedagógico que estavam pautados nas orientações propostas pela Secretaria Municipal de Educa- 
ção. A rede trabalha com uma matriz de conteúdo definido para cada ano escolar em comum para todas as escolas, utilizando o mesmo material de ensino (apostila). As avaliações são realizadas pelo professor, e não existe uma padronização e envolvem mais de uma atividade avaliativa para cada disciplina. Em relação ao grupo estudado, há uma clara especificidade na matriz curricular com foco na leitura, escrita e matemática.

\section{Resultados}

Por se tratar de um estudo de levantamento, foram realizadas análises exploratórias relativas aos grupos de alunos defasados e não defasados com relação ao sexo, tipo de dificuldade mais presente (escrita, leitura e matemática) e predominância de faixa etária. Para fins desse estudo utilizou-se a palavra habilidade para referir-se ao domínio que o estudante apresenta ou não em relação à escrita, leitura e matemática. Essa denominação foi seguida tendo em vista que, na rede municipal em que a pesquisa foi realizada, existe uma matriz curricular que define um conjunto de competências e habilidades a serem desenvolvidas pelos alunos em cada ano escolar.

As competências são entendidas como um conjunto de conhecimentos gerais que servem como guia para as habilidades (indica uma capacidade específica) a serem desenvolvidas. Por exemplo, na leitura, identificar as letras do alfabeto é uma competência, mas reconhecer se as mesmas são maiúsculas e minúsculas, escritas em diferentes padrões e tipos (letras de imprensa ou manuscritas) é uma habilidade.

A primeira análise procurou verificar as diferenças entre os estudantes sem defasagem e com defasagem escolar. No primeiro grupo, os estudantes foram encaminhados por terem sido identificados problemas com o aprendizado da escrita, leitura ou matemática. A maior parte deste grupo foi composto por meninos $(64,4 \%)$ e a porcentagem destes estudantes em relação à amostra total do estudo representou $55,25 \%$. A faixa etária compreendida foi de 6 a 11 anos, com maior incidência na faixa etária de 9 anos $(35,1 \%)$ e que cursavam o $4^{\circ}$ ano $(35,6 \%)$ do ensino fundamental.

Em relação ao grupo com defasagem idade/ano escolar, identificou-se que 75,9\% eram do sexo masculino, constituindo a maior parte desta amostra. A maioria desses alunos (93\%) apresentava defasagem em relação ao ano escolar cursado, ou seja, tinham idade superior ao esperado para o ano que estavam cursando. A maior frequência de defasados estava concentrada nos $3^{\circ}(41 \%), 4^{\circ}(21,7 \%)$ e $5^{\circ}(18,7 \%)$ anos, respectivamente.

Duas situações podem ser inferidas deste dado. Primeira, que $\circ 3^{\circ}$ ano do ensino fundamental parece ser um balizador, pois indica com mais precisão problemas decorrentes da aprendizagem escolar, uma vez que durante $01^{\circ}$ e $2^{\circ}$ ano ainda se considera que os problemas evidenciados fazem parte desse primeiro momento em que as aquisições estão em curso. A segunda é que, passados dois anos de escolarização formal, estas dificuldades, ou atraso na aprendizagem, se tornam mais evidentes e sugerem aos pais e professores a necessidade de buscar uma proposta alternativa para estes estudantes, talvez por isso o maior número de encaminhamentos neste ano escolar. 
Cabe aqui considerar que o setor de atendimento pedagógico tinha como prioridade o atendimento de alunos do $1^{\circ}$ ao $3^{\circ}$ ano do fundamental, e as escolas eram orientadas a respeitar esse critério. Isso porque a rede municipal considerava que no primeiro ciclo do ensino fundamental (do $1^{\circ}$ ao $3^{\circ}$ ano) devem ser introduzidas, retomadas e consolidadas as capacidades definidas nas disciplinas de Língua Portuguesa e Matemática para o ciclo, como: apropriação do sistema de escrita, leitura, produção de textos escritos, desenvolvimento da oralidade, operações com números naturais, resolução de problemas, tratamento de informação, grandezas e medidas, frações, espaço e forma. Os alunos dos anos posteriores também eram atendidos, mas em menor proporção uma vez que o referido setor indicava a participação desses estudantes na recuperação ou aulas de reforço ministradas na própria unidade de ensino. Esta situação faz com que não se possa ter uma ideia real do que ocorre com estes estudantes nos anos subsequentes de escolarização. Com relação à avaliação que foi realizada, compreendendo aspectos relativos da escrita, leitura e matemática, pode-se constatar que a grande maioria dos estudantes sem defasagem apresentou pelo menos algum tipo de dificuldade em alguma dessas aquisições. Dados relativos a essas aquisições encontram-se na Tabela 1.

\section{Tabela I. Análises descritivas do grupo de estudantes sem defasagem idade/ano escolar na avaliação em escrita, leitura e matemática}

\begin{tabular}{l|c|c|c}
\hline & Habilidade ausente & Habilidade presente & Total \\
\hline Escrita & $144(70,2 \%)$ & $61(29,8 \%)$ & 205 \\
\hline Leitura & $71(34,6 \%)$ & $134(65,4 \%)$ & 205 \\
\hline Matemática & $172(83,9 \%)$ & $33(16,1 \%)$ & 205 \\
\hline
\end{tabular}

Fonte: Elaborada pelas autoras.

As avaliações realizadas apontaram que $70,2 \%$ desses estudantes foram identificados com problemas na escrita e, $83,9 \%$, em matemática. Já em relação à leitura, 34,6\% revelaram problemas com esta habilidade. No grupo com problemas na escrita estão os alunos que, de acordo com o ano escolar cursado, não consolidaram o conteúdo desejado. Isso quer dizer que nesse grupo as crianças têm dificuldades para grafar as letras e para reconhecê-las e crianças que, embora alfabetizadas, conseguem escrever palavras com sílabas simples e têm muita dificuldade para ler e entender o que leram. Apresentam, ainda, um pequeno repertório para produzir textos e nem sempre os mesmos são coerentes.

Em relação à matemática, os alunos apresentaram dificuldades para resolver formalmente algumas das quatro operações (ou todas), não reconhecem qual operação é necessária em um enunciado de problema, ainda não escolhem uma unidade adequada de medição na resolução de problemas dessa natureza, têm dificuldade para identificar a decomposição de números em diversas ordens, não percebem informações de tabelas, gráficos e quadros, alguns ainda não identificam unidades de tempo (dia, semana, mês, ano), e não conseguem realizar operações simples de estatística, combinatória ou probabilidade. 
Em relação ao grupo com defasagem idade/ano escolar na avaliação em escrita, leitura e matemática, temos, na Tabela 2, os seguintes resultados:

Tabela 2. Análises descritivas do grupo de estudantes com defasagem idade/ano escolar na avaliação em escrita, leitura e matemática

\begin{tabular}{l|r|r|c}
\hline & $\begin{array}{r}\text { Habilidade } \\
\text { ausente }\end{array}$ & $\begin{array}{r}\text { Habilidade } \\
\text { presente }\end{array}$ & Total \\
\hline Escrita & $116(69,9 \%)$ & $50(30,1 \%)$ & 166 \\
\hline Leitura & $73(44 \%)$ & $93(56 \%)$ & 166 \\
\hline Matemática & $135(81,3 \%)$ & $31(18,7 \%)$ & 166 \\
\hline
\end{tabular}

Fonte: Elaborada pelas autoras.

Em relação à avaliação cognitiva, pode-se identificar que a maioria desses estudantes apresentou problemas com a escrita $(69,9 \%)$ e com a matemática $(81,3 \%)$. Em relação à leitura, embora em mais da metade do grupo não tenha sido identificado problemas, uma porcentagem elevada de estudantes (44\%) revelou atrasos em relação a este domínio. Buscou-se ainda proceder a uma análise mais pontual com relação ao grupo que não possuía as habilidades investigadas, no que diz respeito à prevalência do sexo. Os resultados encontram-se discriminados na Tabela 3.

Tabela 3. Análises descritivas do grupo de estudantes com defasagem idade/ano escolar na avaliação em escrita, leitura e matemática por sexo.

\begin{tabular}{l|r|r|r}
\hline Sexo & $\mathrm{N}$ & Masculino & Feminino \\
\hline Escrita & 116 & $90(77,58 \%)$ & $26(22,42 \%)$ \\
\hline Leitura & 73 & $59(80,82 \%)$ & $14(19,18 \%)$ \\
\hline Matemática & 135 & $101(74,81 \%)$ & $34(25,19 \%)$ \\
\hline
\end{tabular}

Fonte: Elaborada pelas autoras.

Pode-se observar que, além de haver predominância do sexo masculino na amostra geral de estudantes que apresentavam defasagem idade/ano escolar, como exposto anteriormente, também houve predominância desse gênero em relação à ausência das referidas habilidades investigadas, ou seja, maior porcentagem de meninos revelou apresentar problemas com as habilidades de escrita, leitura e aritmética quando comparado ao grupo de meninas e, além disso, essa frequência foi maior com relação à leitura.

\section{Discussão}

Este artigo teve como propósito investigar um grupo de estudantes do ensino fundamental, encaminhados para atendimento pedagógico, por apresentarem baixo desempenho escolar. Foram analisadas as características deste grupo em relação à idade, série, gênero e as dificuldades específicas apresentadas.

Em relação ao gênero, nesta pesquisa os resultados indicam que houve prevalência de meninos tanto no grupo que apresentava defasagem idade/série quanto no 
sem defasagem. Trabalhos que analisam essa questão indicam que o baixo rendimento dos meninos pode estar vinculado ao seu comportamento desatento e desinteressado (Dal'Igna, 2007) e que a indisciplina seria a principal causa de suas dificuldades escolares (Carvalho, 2012). Os meninos apresentam maior número de reprovações e os mais altos índices de defasagem (Palomino, 2004) em contraste com as meninas que obtém maiores índices de sucesso e que demonstram maior aceitação às regras (Carvalho, 2012, Palomino, 2004). Embora no presente estudo se tenha identificado esta prevalência não se pode afirmar que ela seja decorrente das características apontadas pelos estudos anteriores, uma vez que estas características não foram investigadas por este estudo. Contudo, também é importante destacar que, nos Estados Unidos, um estudo conduzido por Bloom, Jones \& Freeman (2012), publicado pelo Summary Health Statistics for U.S. children, revelou que dentre os estudantes que apresentavam algum tipo de dificuldade de aprendizagem, entre 3 e 17 anos, $10 \%$ eram meninos e $6 \%$ meninas.

Há uma escassez de informações sobre a prevalência entre os sexos no que diz respeito ao desempenho em escrita. No entanto, as pesquisas têm apontado para o meIhor desempenho das meninas quando em comparação aos meninos em tarefas de ortografia, escrita e conhecimentos gerais (National Center For Education Statistics, 2013), assim como em tarefas verbais e entendimento das relações lógicas (Hedges \& Nowell, 1995) .

Uma revisão de estudos conduzida por Liederman et al. (2005), relativa à leitura, também revelou que parece de fato haver um predomínio de meninos em relação as meninas com dificuldades. Wheldall \& Limbrick (2010) também analisaram os dados relativos à leitura do New South Wales Basic Skills Test (BST), que é administrado anualmente para estudantes australianos do $3^{\circ}$ ao $5^{\circ}$ graus de escolas de Nova Gales do Sul. Foram analisadas as avaliações realizadas durante os anos de 1997 a 2006. Os resultados deste estudo confirmam pesquisas anteriores de que mais meninos que meninas apresentam problemas de leitura. No entanto, apontam que diferenças na incidência podem ser mais modestas do que as pesquisas anteriores sugeriram. Com relação à matemática, estudos indicam melhores resultados dos meninos, quando comparados ao das meninas (Hedges \& Nowell, 1995; Geary, 1996; Spelke, 2005; Wai, Cacchio, Putallaz, \& Makel, 2010; Halpern, 2012).

Olhando para estudos anteriores e para o que aponta a literatura pode-se afirmar que os dados revelados por este estudo confirmam em parte esses achados, mas, por outro lado, também precisam ser analisados e interpretados com mais cautela. Considerando a questão da prevalência em relação aos sexos, no que diz respeito às dificuldades com a aprendizagem escolar, pode-se dizer que este estudo confirma a tendência geral apontada na literatura que é de maior prevalência de meninos que de meninas nessa população. No caso específico desta amostra pode-se dizer que há maior quantidade de meninos encaminhados para atendimento ou que, ao serem avaliados, são identificados como um grupo que necessita de mais acompanhamento. 
Por outro lado, ao se analisar a porcentagem de meninos e meninas que não possuem as habilidades investigadas, ou seja, escrita, leitura e aritmética, os dados necessitam ser interpretados com mais cautela, tendo em vista que houve sempre maior prevalência de meninos com problemas nessas três habilidades. Este dado, no entanto, não nos permite afirmar que os meninos têm pior desempenho que as meninas nessas três habilidades. É importante destacar que essa população apresenta um viés, que diz respeito ao fato de que são crianças encaminhadas a um serviço de apoio pedagógico, e não provenientes de um contexto de sala de aula regular, e que os critérios adotados pelos professores, para esse encaminhamento, são subjetivos e podem ser bastante diferentes entre si e que a avaliação conduzida também tem especificidades que diferem do contexto de sala de aula.

Comparando nossos dados de distorção idade/ano escolar com as taxas nacionais, divulgadas pelo Instituto Nacional de Estudos e Pesquisas Educacionais Anísio Teixeira (2015), pode-se verificar que na amostra investigada a porcentagem de alunos em defasagem no $3^{\circ}$ ano escolar era de $41 \%$, no $4^{\circ}$, de $21,7 \%$ e, no $5^{\circ}$ ano, de $18,7 \%$, enquanto os dados oficiais revelam a percentagem de $21,6 \%$ no $3^{\circ}$ ano, $24,4 \%$ no $4^{\circ}$, e $25,5 \%$ no $5^{\circ}$. É importante destacar que os dados da presente pesquisa se referem a uma amostra de estudantes que frequentavam um serviço de atendimento de um município do estado de São Paulo, enquanto o Inep apresenta dados nacionais e relativos aos estudantes que estão frequentando a escola regular.

Nos dados nacionais, verifica-se que os anos finais do primeiro ciclo do ensino fundamental configuram-se como os de maior prevalência de distorção idade/ano escolar, contrariamente ao encontrado neste estudo. Essa diferença pode residir no fato de que a política de progressão continuada foi interpretada de maneira muito diferente pelos respectivos municípios, sendo muitas vezes entendida como impeditiva de reprovação dos alunos nos anos iniciais e sendo somente aplicada no final do ciclo. Essa forma de interpretação, e condução desta política, pode ser a responsável pelas diferenças encontradas entre os dados nacionais e municipais aqui apresentados, uma vez que o município investigado segue uma orientação de reprovar o aluno caso o mesmo não atinja os mínimos requisitos definidos na matriz curricular. Outro motivo que pode ter contribuído para as diferenças observadas pode estar no fato de que no município investigado havia uma recomendação de atendimento prioritário aos alunos do $1^{\circ}$ ao $3^{\circ}$ ano escolar.

Por fim, ao analisar em quais conteúdos (escrita, leitura e matemática) havia maior prevalência de estudantes, observou-se que em ambos os grupos, com e sem defasagem, a escrita se apresenta como o principal fator de defasagem, isso porque os estudantes não conseguem produzir textos coerentes, sem erros de ortografia ou gramática e apresentam um repertório reduzido de palavras, ou seja, são conhecimentos que já deveriam estar consolidados ou mais avançados do que estavam, e que não estão sendo adquiridos pelos estudantes. 


\section{Considerações finais}

Tem sido cada vez mais frequente encontrarmos estudos realizados em diferentes países por órgãos oficiais dos governos ou conduzidos por pesquisadores independentes que tenham se detido a investigar o desempenho escolar dos estudantes, de diversos níveis de ensino, com relação aos domínios exigidos pela escola. Ainda que muitas críticas possam ser feitas a esses estudos, alegando-se que podem acentuar as diferenças entre os estudantes ou até mesmo responsabilizá-los por suas dificuldades, também é sabido que estudos dessa natureza têm sua relevância reconhecida, à medida que colocam em evidência e discussão o papel desempenhado pelas escolas no processo de formação dos estudantes, bem como têm permitido a problematização dessas instituições e o trabalho pedagógico por elas desenvolvido.

A análise dos dados nos encaminha para a reflexão de dois aspectos: a diferença entre os gêneros e seu comportamento, e as habilidades dos estudantes. Primeiro, em relação ao trabalho da escola, chama a atenção o fato de os meninos serem, em sua maioria indicados para atendimento e configurarem, como apontado em outras pesquisas, (Carvalho, Senkevics, \& Loges, 2014; Pinto, 2004; Henriques, 2002) maior percentual de reprovação e evasão escolar. Sendo os meninos um diferencial de comportamento e de desempenho, como essa diferença de gênero vem sendo tratada na escola? Será que os meninos representam um perfil de comportamento que a escola considera inadequado?

Para Carvalho (2012) existe no Brasil uma representação difundida na avaliação dos professores de que os bons alunos são participativos, críticos e obedientes. Nesse sentido, as meninas seriam mais adequadas à escola enquanto os meninos, por serem mais indisciplinados e desorganizados, tornam-se incompatíveis com esse modelo de exigência escolar. Soma-se o fato de alunos com problemas de comportamento serem encaminhados para reforço escolar ou atendimento, sem terem efetivamente um problema de aprendizagem, ou seja, de natureza cognitiva, o que é um indicativo da influência comportamental sobre a cognição e da dinâmica das relações em sala de aula.

Mediante o exposto, os dados conduzem à reflexão sobre a necessidade de se criar um espaço - seja na escola, seja nos cursos de formação de professores - para a análise das relações entre crianças em sala de aula, das diferenças comportamentais e das representações docentes criadas a partir desses protótipos de comportamento, bem como a questão do desempenho escolar.

Por fim, quando pensamos nas habilidades e/ou competências, como se pode explicar que alunos no início do ensino fundamental não consigam atingir os requisitos mínimos para a série e estudantes no final do ciclo ainda não saibam ler e escrever? Isso é uma realidade nas escolas públicas brasileiras, evidenciada pelos resultados dos testes em larga escala e pelas próprias escolas, quando se verifica os índices de alunos que não conseguem acompanhar os conteúdos escolares. O fato de alunos serem promovidos sem ter o mínimo de conhecimento é regra e não exceção que pode ser explicada por Carvalho (2012) ao afirmar que existe pressão para que não sejam atribuídos conceitos negativos aos alunos e que ao final do ciclo só um número pequeno 
seja retido, reforça a prática da aprovação automática, o que justifica crianças chegarem às séries finais sem o domínio do conhecimento. Ou seja, ter seu direito garantido à educação não garante uma educação de qualidade que efetive a aprendizagem e o pleno desenvolvimento dos estudantes.

Essa pesquisa possibilitou analisar um grupo de estudantes que frequentavam atendimento pedagógico por apresentarem baixo desempenho escolar. Os resultados indicam que a maior parte dos estudantes encaminhados são meninos, o que configura prevalência quanto ao gênero, no entanto, uma das limitações desta pesquisa incide sobre a não comparação das diferenças entre meninos e meninas em relação ao campo de conhecimento em defasagem, o que abre novas possibilidades de estudos e que mereceria atenção futura em outras pesquisas.

\section{Referências}

Bloom B., Jones L. I., \& Freeman, G. Summary health statistics for U.S. children: National Health Interview Survey, 2012. (2013). National Center for Health Statistics. Vital Health Stat 10(258), 1-81.

Carvalho, M.P. (2004). Quem são os meninos que fracassam na escola? Cadernos de Pesquisa, v. 34, n. 121, jan./abr.

Carvalho, M. P. (2012). Teses e dissertações sobre gênero e desempenho escolar no Brasil (1993-2007): um estado da arte. Pro-Posições, 23(1), 147-161.

Carvalho, M. P., Senkevics, A. S., \& Loges, T. A. (2014). School success of girls from poor communities: what is the role of family socialization?. Educ. Pesquisa, São Paulo, v. 40, n. 3, p. 717-734, set. Disponível em <http://www.scielo.br/scielo. php?script=sci_arttext\&pid=S1517-97022014000300009\&lng=pt\&nrm=iso>. Acesso em: 1 mar. 2017. http://dx.doi.org/10.1590/s1517-97022014091637.

Cortiella, C. H., \& Sheldon, H. (2014). The State of Learning Disabilities: Facts, Trends and Emerging Issues. New York: National Center for Learning Disabilities. Disponível em: < http://www.ncld.org/wp-content/uploads/2014/11/2014-State-of-LD-FINAL-FOR-RELEASE.pdf>.

Dal'Igna, M. C. (2007). Desempenho escolar de meninos e meninas: há diferença? Educação em Revista, Belo Horizonte, 46, 241-267.

Felicio, F. (2009). O ensino fundamental - desafios desde a alfabetização até a transição para o ensino médio. In Veloso, F., S. Pessôa, R. Henriques, \& F. Giambiagi, F et al. Educação básica no Brasil: construindo o país do futuro. Rio de Janeiro: Elsevier.

Geary, D. C. (1996). Sexual selection and sex differences in mathematical abilities. Behavioral and Brain Sciences, 19, 229-284. 
Gouvea, G. F. P. (2000, março). Um salto para o presente: a educação básica no Brasil. São Paulo Perspec., 14(1), 12-21.

Gregoriadis, A., \& Tsigilis, N. (2008). Applicability of the student teacher relationship scale (STRS) in the Greek education setting. Journal of Psychoeducational Assessment, Sage Publications, 26(2), 108-122.

Halpern, D. F. (2012). Sex differences in cognitive abilities (4th ed.). New York: Psychology Press.

Hedges, L. V., \& Nowell, A. (1995). Sex differences in mental test scores, variability, and numbers of high-scoring individuals. Science, 269, 41- 45.

Heitin, L. U. S. (2013). Girls Perform Evenly With Boys in Math and Science. Education Week, December. Disponível em: http://blogs.edweek.org/edweek/curriculum/2013/12/pisa_us_girls_perform_evenly_w.html.

Henriques, R. (2002). Raça e gênero nos sistemas de ensino: os limites das políticas universalistas em educação. Brasília: Unesco.

Instituto Nacional de Estudos e Pesquisas Educacionais Anísio Teixeira (2015). Taxas de distorção idade-série escolar na educação básica. Disponível em: http://dados.gov. br/dataset/taxas-de-distorcao-idade-serie-escolar-na-educacao-basica.

Liederman, J., Kantrowitz, L., \& Flannery, K. (2005). Male vulnerability to reading disability is not likely to be a myth: a call for new data. Journal of Learning Disabilities, 38(2), 109-129.

Limbrick, L.; Wheldall, K.; and Madelaine, A. (2010) "Estimating Gender Ratios of Poor Reading Using Large-Scale Assessments," Australian Journal of Education: Vol. 54 : Iss. 2 , Article 5. Available at: http://research.acer.edu.au/aje/vol54/iss2/

Mandeli, M. (2011). A escola deve organizar a aprendizagem. Disponível em: <http://www.estadao.com.br/noticias/geral,a-escola-deve-organizar-aaprendizagem-imp-,815289>. Acesso em jan. 2016.

National Center for Education Statistics. (2013). Gender Differences in Science, Technology, Engineering, and Mathematics (STEM) Interest, Credits Earned, and NAEP Performance in the 12th Grade, USA. Disponível em: https://ies.ed.gov/ pubsearch/pubsinfo.asp?pubid=2015075.

Organization for Economic Co-operation and Development - OECD. PISA (2012). Results: What students know and can do: student performance in matematics, reading and science (Vol. I). OECD Publishing. Disponível em: http://dx.doi. org/10.1787/9789264201118-en.

Oliveira, R. L. P. (2011). A qualidade do ensino como parte do direito à educação: um debate em torno dos indicadores. In S. Z. Pinho (Org.). Formação de educadores: dilemas contemporâneos. São Paulo: Editora da Unesp. 
Osti, A., \& Martinelli, S. C. (2014). Desempenho escolar: análise comparativa em função do sexo e percepção dos estudantes. Educação e Pesquisa, 40(1), 49-59. Epub September 27, 2013. Retrieved March 01, 2017, from http://www.scielo.br/ scielo.php?script=sci_arttext\&pid=S1517-97022014000100004\&Ing=en\&tIng=p.

Palomino, T. J. (2004). Meninos e meninas em escola de periferia urbana: a relação entre fracasso escolar e sexo, cor e organização familiar. Dissertação de mestrado, Universidade Federal de São Carlos, São Carlos, SP, Brasil.

Relatório Nacional Pisa (2012). Resultados brasileiros. Recuperado em 2 abril, 2015, de http://download.inep.gov.br/acoes_internacionais/pisa/resultados/2014/relatorio_nacional_pisa_2012_resultados_brasileiros.pdf.

SÃO PAULO (Estado). Desempenho Escolar 2010 - 2013. Governo do Estado de São Paulo. Secretaria De Estado Da Educação. Coordenadoria de Informação, Monitoramento e Avaliação Educacional - CIMA / SEESP, 2014. Disponível em: <http:// www.educacao.sp.gov.br/a2sitebox/arquivos/documentos/814.pdf>.

Souza, F. (2007). Desvendando práticas familiares e escolares a partir das relações de gênero: uma reflexão sobre a educação de meninos e meninas. Tese (Doutorado) - Educação, Universidade Estadual Paulista Júlio de Mesquita Filho, Araraquara.

Spelke, E. S. (2005). Sex differences in intrinsic aptitude for mathematics and science? A critical review. American Psychologist, 60, 950-958

Stoet G, Geary DC (2013) Sex Differences in Mathematics and Reading Achievement Are Inversely Related: Within- and Across-Nation Assessment of 10 Years of PISA Data. PLoS ONE 8(3): e57988. doi:10.1371/journal.pone.0057988.

Veloso, F. (2009). 15 anos de avanços na educação no Brasil: onde estamos? In F. Veloso, S. Pessôa, R. Henriques \& F. Giambiagi, F. Educação básica no Brasil: construindo o país do futuro. Rio de Janeiro: Elsevier.

Wai, J., Cacchio, M., Putallaz, M., \& Makel, M. C. (2010). Sex differences in the right tail of cognitive abilities: A 30-year examination. Intelligence, 38, 412-423.

Submissão: 18.9.2015

Aceitação: 14.9.2016 